\title{
Finding a change champion
}

\section{Kenny Kirsch}

is Director of Strategic Solutions at NAPC, a leading technology integrator and developer serving some of the biggest names in advertising, publishing, retail and printing. Kenny has deployed DAM systems for many clients, including Pepsi and IBM, and specializes in technology solutions based on Xinet. He has over 15 years of experience in digital print production and asset management, and was previously Director of Studio Services at TracyLocke (a division of DAS/Omnicom) and VP, Director of Graphic Services at EuroRSCG (a division of Havas).

Keywords: change, champion, leadership, NAPC, Xinet

Abstract Offering insights for both team leaders and top management, this article focuses on the unique set of skills required to successfully lead a digital asset management implementation. Organizations will learn what criteria to look for in choosing a top project leader (or change champion) and gain a better understanding of the formidable challenges this individual faces. This article also delves into the common mistakes companies make in carrying out their change management initiatives, from choosing the wrong leaders to giving them inadequate support. For change champions, there are guidelines on how to build an implementation plan, with advice on critical topics such as performing a business audit, understanding the company's business problem and rolling out a training program.

Journal of Digital Asset Management (2006) 2, 237-241. doi:10.1057/palgrave.dam.3650038

\section{INTRODUCTION}

While choosing the right technology is important, there's another critical factor that will ultimately determine the success or failure of your digital asset management (DAM) implementation. And that is whether you have a "change champion" in your organization with the will and skill to make it happen.

After all, choosing and implementing a DAM system can be a heroic undertaking. It requires an individual at the helm who can see the big picture, understand the differences between technologies, solve problems, get buy-in from top management, gain acceptance from end users and much more. Having a task force or change management team in place is important, but it's not enough. You need a leader who can take control of the entire process. You need a change champion.

As a leading technology integrator, my firm (NAPC) has developed an excellent prequalification process for identifying a change champion with the right stuff. In fact, we offer an in-depth training course on the topic to help companies start off on the right foot. In this editorial, I'd like to share some of our insights as well as some of the lessons we've learned about how to increase your change champion's chances of success.

\section{QUALIFICATIONS OF A CHANGE CHAMPION}

Finding the right candidate isn't easy. But you'll be much more likely to spot a champion if you look for someone who possesses the following qualifications:

Holistic view of the company: Because a DAM system will affect all parts of your operation, you need a change champion who understands all parts.

You don't want someone with tunnel vision who's narrowly focused on his or her specific job responsibilities. Instead, seek out an individual who has worked in different departments, climbed through the ranks and demonstrated a strong interest in understanding what everyone in the company does.

Too often, change champions aren't familiar with the creative processes or workflows that users follow. To them, a DAM system is merely a library or a purchasing decision. They don't understand which processes will be affected because they don't live in that world day to day.

In addition, a change champion has to be able to cross all boundaries. That may include gaining access to clients, becoming involved in intranets and extranets or acquiring expertise in a wide range of topics like rights management and metadata. The point is, you can't have a 
siloed perception as change champion. You need a holistic view.

Technical understanding: The change champion must have an in-depth knowledge of DAM technologies - or be a quick study. This person will need to demonstrate the technology internally and externally — to get approvals, build consensus and convince clients that DAM is a compelling new capability offered by the company or agency.

Troubleshooting ability: Being able to troubleshoot and problem-solve is critical because no matter how much due diligence you do, problems will arise. I had the opportunity to oversee one of the first Xinet installs in a completely OS X environment. Within the first hour after everything was up and running, files started disappearing. Instead of pointing a finger at the vendor - which I might have been justified in doing - I enlisted them as an ally and together we solved the problem. The lesson here is figure out how to succeed, not who to blame.

Passion and drive: As the driving force behind change, the change champion must be passionate about the technology itself, committed to reshaping any parts of the company's culture that would resist change, and driven to succeed no matter what the obstacles.

Respect among peers: Will people follow you down this new path? Keep in mind, your title or position will only get you so far in gaining their support. To be successful, you have to have been a user. You have to be able to talk shop and connect with users. Above all, they have to believe that you understand how this change will affect them.

Support from top management: If top management is not behind you, your project is doomed from the start. A project of this scope requires resources and support that can only come from the top. I recently talked to a firsttime change champion at a big agency and she said to me, "Our president will never understand this." That's a big problem. You need to make them understand.

Risk tolerance: Quite simply, a change champion has to have a backbone. Different people and situations will thoroughly test your mettle. You need to have confidence that if your project isn't going according to plan, you won't be escorted out the door.

\section{COMMON PITFALLS IN MANAGING CHANGE}

Many companies struggle mightily to implement DAM systems. Some never get to where they want to be. Take a closer look and you'll undoubtedly find some common pitfalls.

\section{Incomplete qualifications}

As outlined in the previous section, the change champion has to have an impressive range of skills. A number of companies look for only two or three of these qualifications, which is inadequate. The change champion they appoint might be a business person or a technology person, but not both. This lack of perspective can doom a project from the start.

\section{III-fated executive appointments}

Given the importance and magnitude of implementing a DAM system, the project should be managed by a high-level executive, right? Actually, that's one of the biggest mistakes a company can make. Instead of choosing someone who's involved and engaged in the day-to-day workings of the company, they'll choose an executive who's completely removed from the situation. While the change champion certainly needs access to top management, as well as their blessing, this individual shouldn't necessarily come from the ranks of top management.

\section{Inadequate preparation and support}

The change champion should be involved before the technology is bought. As the linchpin for the entire effort, the change champion needs to have a major say in both the technology chosen and the team picked to select it and support it.

Instead of a dedicated DAM team, some companies lean on their information technology (IT) departments for support, calling them in like mechanics if something needs fixing. That's doesn't work. You need a "pit crew" that is integrated from the start and knows all the issues. A DAM implementation is not a project you can jump in and out of.

\section{Conflicting responsibilities}

The change champion needs to clear his or her plate of other responsibilities. The change champion's manager needs to recognize the time 
needed to be sole proprietor of this project, and allow the change champion to offload other responsibilities or hire others to handle the workload. There's nothing more detrimental to your project than having a change champion pulled in two different directions - between day-to-day responsibilities and change management responsibilities.

Similarly, the people on the change champion's task force should be freed of some of their regular responsibilities as well. If they're sitting in meetings checking their email, or telling you they didn't have time to do something because they were too busy with other tasks, that puts more of the onus on you as the change champion. If someone on your task force is a weak link, it had better be in an area that's your strength.

\section{Culture shock}

People resist change. It's human nature. The question is, how do you get them to come around and embrace change?

I've seen CEOs stand up before employees and declare, "We're all going to use this new technology." That's a joke. Without laying the proper groundwork, no one's going to be on board.

The key thing to remember is that people want to know what's in it for them. As the change champion, you've got to figure out how to appeal to all these people and departments, and really understand how change will affect them. Expect a certain amount of culture shock - not only from people internally but also from clients, partners and remote offices.

During this process, it's important to be sensitive to people's needs. At one agency where I worked, our new DAM system changed the way people sent files to vendors. One guy in production - who was somewhat of a technophobe - wanted to continue sending files by FedEx, a more manual and timeconsuming process. At the time, I wasn't sensitive to his resistance to change. Now I make sure we thoroughly demonstrate the advantages to the different people and departments affected through a well-planned training process.

Of course, you can minimize a lot of the resistance by choosing your technology wisely. A lot of change champions don't understand that the methods used by certain DAM technologies
- such as a check-in, check-out method of retrieving assets - force users to learn new behaviors. People don't want to learn new behaviors. They want better behaviors. To give you an analogy, don't teach them how to drive with a stick shift if they're used to automatic. Just give them a faster car.

\section{Over-reliance on vendors}

Every company with a DAM installation should have their own pit team. Don't expect your vendor to be your pit team. While they may train your team, it's a mistake to think they'll take care of everything for you all the time.

The team that deals with your DAM installation needs to be inside your company. Internal processes must be established and nuances must be learned. When little things go awry, companies will often turn to their vendors and say, "But I paid you a lot of money!’Yes, but to teach you what you need to know, not to continually manage typical day-to-day issues that arise.

\section{CHANGE CHAMPION'S GUIDE TO BUILDING A PLAN}

Now that you know what to avoid, let's look at how the change champion should go about building a plan for implementing a DAM system.

\section{The all-important audit}

Too often, companies get sucked in by a great RFP/RFI, which gives them a false sense of security that everything will go exactly as planned. Smarter companies will take the ounce-of-prevention approach. They will thoroughly plan and research. They will do due diligence to ensure a successful outcome. And most important, they will perform an audit of other installations.

I can't overemphasize the need for an audit. Your company, led by your change champion, needs to talk to other companies that have done similar things. You need a reference point on who's succeeded at this, who's failed and why.

The first step is to find organizations like yours that have implemented a DAM system. Talk to your colleagues in the industry. Or ask a vendor to put you in touch with some of their clients. If they're reluctant to give you names, that may be a good indication that you should steer clear of that vendor in the future. 
Keep in mind, you're looking for real-world experiences and real-world success stories qualitative and quantitative evidence of the results others have achieved. For example,

- How much are their distribution costs down?

- Do they have fewer rounds of revisions now?

- Are their production people more efficient?

- Is there less work for their art buyers?

- Are they getting materials to press faster?

- Are they making fewer rights management errors?

I'd even go the extra step of talking to clients of these companies. For example, ask the global marketing client - the one whose assets are being managed and distributed by an ad agency - if she's as excited about the DAM system as the agency seems to be. If the feedback isn't consistent, that might be a warning flag.

\section{The business problem}

The change champion must know what business problem the technology will solve. That may sound obvious but you'd be surprised how many companies lose sight of that. If you can't articulate how the technology will positively impact what you do, you may end up choosing the wrong technology. If all you know is you need to manage assets, you'll fail.

Take a long, hard look at what you need from an asset management system. Delve into how your company uses its graphic assets. Find out the answers to questions like these:

- Are your assets static or dynamic?

- Do you need a repository of finished work only or a production environment where graphic assets are always changing?

- Will your DAM system be used for worldwide distribution of assets?

- Will it be used only for rights management so you can better manage what you buy without violating any agreements?

- How will it affect other offices in the company will it comply with their processes?

- What is the global scalability of the system - not just today but a couple of years from now?

The first time I had to choose a DAM system, I spent 5 months devising a methodology, showing it to other people and refining it. Along the way, I changed course several times. It's important not to rush into a decision you'll later regret.

\section{Training}

How are you going to train people? Will you create a CD that you distribute? Hold sessions? What? Here are some of our time-tested tips for training:

- Make your training materials as condensed as possible.

- Don't let people run the new system concurrently with the old technology, because it will be too tempting for them to fall back on what they know.

- Don't roll it out in small groups. It's better when everyone has the feeling of being in this together.

- Big training groups are better than small ones, but segment it by user type - for example, have one session for art buyers and another for art directors - because different users will use the system in different ways.

- Roll out features incrementally so it's easier to manage and troubleshoot.

- Train offsite if possible, without all the distractions of the workplace.

\section{Service provider}

Choose a provider who wants to be a partner, not just a seller. And make sure it's a company that has a strong knowledge of what your business does. You want a company that is innovative but cautious, up on the latest technology but always mindful that your business has to keep on running.

\section{Budget}

You need to make a good business case to management. It helps if you can point out new revenue opportunities or cost-savings that will result. Also, be sure to buy something scalable, where you can add licenses or new components when you need to.

\section{Timeline}

There is no standard guideline for how long a project should take. But once your project is underway, it's important to keep a sense of urgency, especially in the later stages. As the change champion, you've really got to push to make this happen. You've also got to plan for the future. Companies tend to look at these 
projects as one-time installations. They think you do it and you're done. But you're not. You need to have an ongoing plan for updating and maintaining the system.

\section{Contingencies}

What happens if your change champion leaves? Is there a right-hand man (or woman) who can take over? What happens if something goes wrong? Have you thought about worst-case scenarios?

Having a good internal pit team to carry on - as well as a good integrator with the ability to provide training — can help bridge any gaps.

\section{A MAKE-OR-BREAK OPPORTUNITY}

Becoming a change champion is a careerdefining move, for better or for worse. If you fail, your job may be at risk. If you succeed, your profile within the company is sure to increase significantly.

True change champions can be the difference between expensive boondoggles and highly efficient organizations. As such, they deserve to be rewarded. When they rise to the occasion, be sure to take good care of them. Otherwise, they'll quickly be putting their skills to use for someone else.

Above all, when implementing a DAM solution, remember that it isn't only about the technology. With a project of this scope - one requiring a coordinated launch effort and affecting many users throughout your organization - people are your most important asset. And no one is more important than your change champion. 